\title{
Rendering a dangerous healthcare ocean safer
}

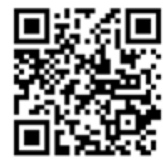

Take a tidal wave of patients, a trickle of specialists and a small shoal of medical students eager to palpate, probe and prick (at the very least), and mix them together in the public sector sea for several consecutive years. No CPD points for guessing the range of adverse events that can follow, and inevitably will.

The reality is that these ongoing ratios cost provincial health authorities billions of rands in litigation payouts every year, never mind - in a best-case professional scenario a debilitating knock to the confidence of overworked and undersupervised doctors and nurses.

Yet one single, carefully considered crossdisciplinary intervention that trains pre- and postgraduate medical professionals correctly, without harming anyone or repeatedly invading the privacy of patients, is making a difference at Groote Schuur Hospital (GSH), and far wider afield.

The University of Cape Town (UCT)'s publicly and privately funded simulation hub, spread across three spaces in the hospital, populated with high- and lowfidelity manikins and equipment, and staffed by several full- and part-time experts (both generalist and specialist), is an enviable hybrid teaching model. Dr Rachel Weiss, Director of the UCT Clinical Skills Centre and an expert in curriculum design and education, puts it succinctly: 'Here you can give standardised teaching to everyone, without harming patients or imposing a major teaching burden on busy specialists.' That's not to say they don't regularly call on specialists to teach and supervise certain procedures - that's still a pragmatic, but now lower-impact, necessity.

\section{An 11-year journey}

Started in 2004, the Clinical Skills Centre has grown exponentially via progressive budgeting and tailored specialist equipment company funding. Today it has a simulation laboratory with traditional simulation equipment, a 'patientless' simulated ward, and a health and rehabilitation laboratory all organised according to functions, not disciplines, in what Weiss describes as 'an important ideological step towards integrated, multidisciplinary training. She has helped source private sector funding

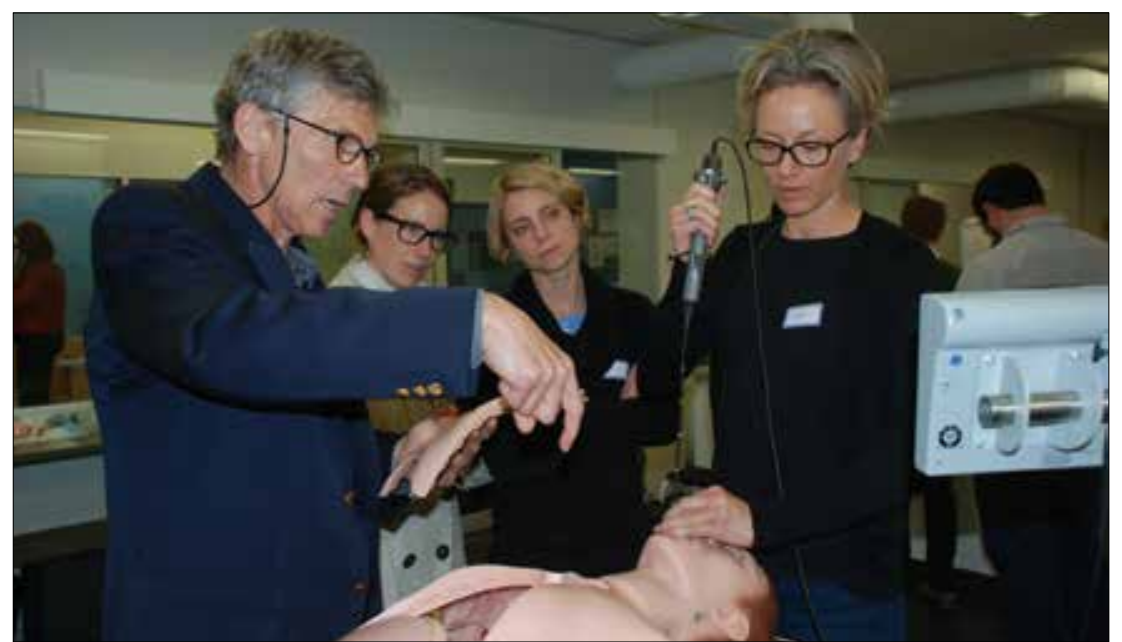

Anaesthesiologist Dr Andrie Alberts leads colleague Dr Ulla Plenge through a procedure.

for two young anaesthesiologists who have a passion for developing simulation-based education. Izindaba watched postgrad students acquire endoscopy skills, guiding instruments past life-like swollen airways, down 'burnt' throats and past tumours, not to mention doing a needle cricothyroidotomy (aka 'crike' or emergency airway procedure) - basically a range of airway problems that it might take years to encounter, let alone perfect, in a clinical patient setting.

\section{Setting up and maintaining a} simulation lab is an expensive but ultimately cost-effective exercise. An advanced life support 'casualty' manikin costs R140 000, while the price tag for a programmable, wireless 'theatre' manikin is close to R1 million 'we wouldn't let third-years near him', quips Weiss. The useful lifespan of a manikin is 5 years, while all machines need constant calibration.

When it comes to undergraduate programmes, simulation is 'scaffolded' to build skills longitudinally. Take emergency medicine training for medical students: while first-year students do basic life support as taught to lay people, third-years progress to intermediate life support using a bagmask device and automated and manual defibrillators. Fourth-years are taught how to intubate a patient during resuscitation and to work with different kinds of drugs (e,g. cardiac resuscitation drugs) and advanced treatment algorithms, building skills towards difficult intubations and intravenous access (central and other forms of vascular access). By fifth year they're pacing and 'cardioverting' patients with lethally slow and fast heart rates. 'We also teach the so-called 'soft skills': how to work as a team around a bed, function as a team leader and communicate effectively in high-stress environments, so by sixth year they are able to run a full resuscitation scenario by themselves, taking responsibility for keeping somebody alive until more competence arrives.'

\section{Costly but hugely \\ effective}

Setting up and maintaining a simulation lab is an expensive but ultimately cost-effective exercise. An advanced life-support 'casualty' manikin costs R140 000, while the price tag for a programmable, wireless 'theatre' manikin is close to R1 million - 'we wouldn't let third-years near him', quips Weiss. The useful lifespan of a manikin is 5 years, while all machines need constant calibration.

Weiss and her anaesthesiology colleagues, each of whom has a pet project that is either currently adding major value to the teaching programme or soon will be, via 'cyber-reach', believe in getting the basics right. 'Patient safety is our first priority; for example, to inculcate a lifelong respect for infection control, second-year students start with hand-washing 


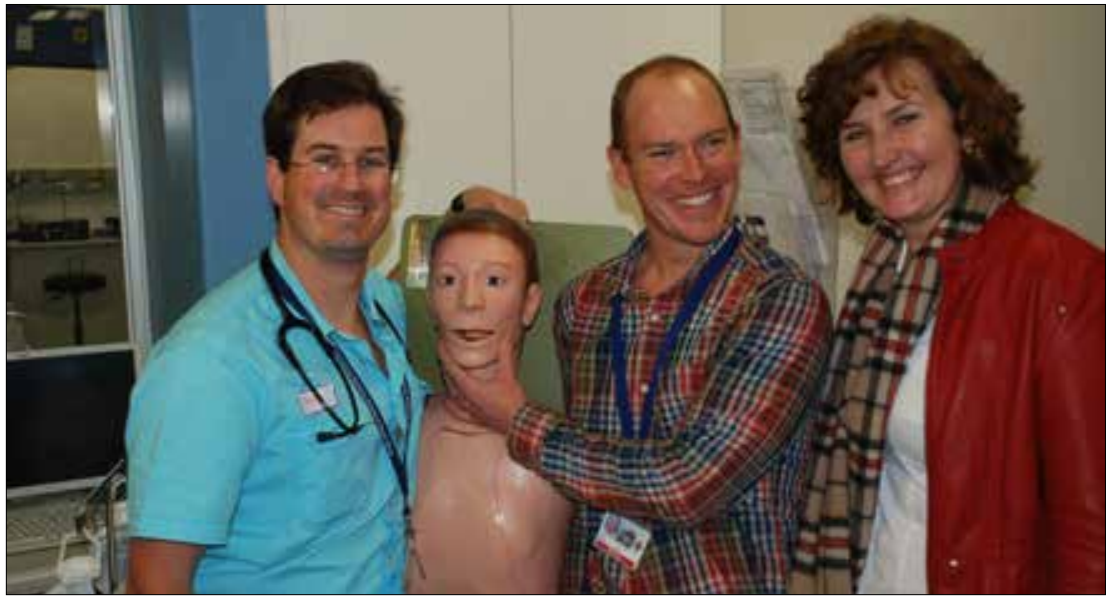

UCT clinical simulation lab stalwarts Drs Ross Hofmeyr, Rowan Duys and Rachel Weiss.

(a talk from an infection control nurse whose favourite trick is to put students' hands under a 'glitter-bug' light to show just how many bugs they're carrying), while our third-years prepare sterile trolleys for blood cultures or learn how to create a sterile field while suturing.' It is not only the patient who is at risk in a hospital; healthcare workers have a high risk of contracting tuberculosis (TB) from infected patients, or blood-borne diseases such as HIV and hepatitis during needlestick injuries. The centre fits and supplies every student with TB respirators in the wards and works with activist group TB PROOF to break the silence around occupational TB. A partnership with Becton Dickenson, manufacturers of safety needles, actively promotes sharps awareness and ensures that students receive intense, small-group, supervised practicals with a range of different safety devices. Simulation-based training provides opportunities to standardise care; instead of 'see one, do one, teach one' in the ward, students can (for example), insert intercostal drains on pork ribs or manikins repeatedly until they get it right. Here's where the real diamonds on the training sea-bed lie; simulation means less risk to patients, students speedily improving hand-to-eye co-ordination skills, and more people taught in less time. 'You can stop and correct errors and re-do things. We see them making a mistake and we stop that before it gets ingrained. It's optimal and repeated practice. As a student you may never get a chance to do this stuff before your internship. Here you learn, so that one day when you end up in a deep rural hospital, people don't die from preventable errors.'

\section{Giving patients their humanity back}

One of Weiss's dreams is to start a 'patientpartner' programme, recruiting a small group of jobless people with manageable conditions (mild cardiac failure or hypertension) to simulate situations and help teach medical students how to communicate by giving them feedback. Weiss says the more junior the doctor, 'the more they tend to palpate the patient's liver repeatedly to learn' - not ideal for tertiary inpatients lying vulnerable in a ward. 'We did a study in 2011 and found that patients are completely disempowered. They sometimes get students coming up to them five times a day to practise on them - and they still say yes!'

'We have a lot of patients here who cannot work because of their condition, so this would be job creation and they'd replace the patients in the actual wards. Our in-hospital patients are really ill - so it's actually a human rights issue, she adds.

Dr Rowan Duys, an anaesthetist and recent Fellow in Simulation and Education (partially funded by Dräger, which also donated ZAR10 million in medical equipment to the centre), takes time off from leading a simulation to tell me that as far back as second year, he can remember wondering what the point was of learning to 'look after the patient in front of you when the system around you is broken'.

\section{applies his life lessons}

What stuck from Duys's internship at George Mukhari Hospital, north of Pretoria, was 'the amazing individual clinicians but a real lack of leadership and training, while his community service at Hlabisa Hospital in northern KwaZulu-Natal helped hone his survival skills. Subsequent work in the NHS in the UK first exposed him to simulation training and taught him that minimum standards there were far better protected and that the UK 'holes in the net' for patient care were far smaller than locally. His more recent registrar time here left him painfully aware of the stark differences in

\section{Anaesthesiologist}

skills levels between UK nurses and their local counterparts - and the differences in training methodology. 'I developed a real passion for developing nursing education and skills levels and finding innovative ways to train people better, he says, explaining a journey that led him to approach Dräger to fund his current post from August this year. Nearly 5 years ago he began training a short course in anaesthesia to GSH (and other) nurses using the simulation lab for scenariobased training. In simulation he sees three major areas: technical skills, crew resource management (team interaction, leadership and communication skills), and systems testing and development - which can lead to a latent risk or adverse event being identified during simulation that one can report as a real-time human event, one of the more hidden lifesaving benefits.

\section{'Here you can give standardised teaching to everyone, without harming patients or imposing a major teaching burden on busy specialists.'}

\section{Mitigation in a}

\section{dysfunctional system}

Duys's colleague Dr Ross Hofmeyr is the Storz Fellow in Airway and Thoracic Anaesthesia (predominantly funded by Storz, manufacturers of endoscopy equipment), and has tellingly similar motives. 'If I'm a highly skilled anaesthetist working in a dysfunctional system, my patients will get poor care, no matter how good I am! You can try and tackle that from a management point of view or a political point of view, but I want to tackle it from a training and education angle', he asserts. As far as he knows, he and Duys are the only Cape metropole consultants (across disciplines) taking up either partor full-time educational roles. Hofmeyr says that while anaesthesia is generally very safe, it has a zero tolerance for adverse outcomes. 'Nobody ever got better because of anaesthesia - everything we do places the patient at risk, yet there are low-frequency, high-risk events which we don't see often, but they have dire consequences.' It is here that simulation can avoid things like anaphylaxis, malignant hypothermia, major haemorrhage or difficult intubation. 'You hardly ever get to practise these, but you're supposed to be good at managing them,' he adds. His 'extra value add' to the Clinical Skills Centre is developing a utilitarian e-learning platform for nurses by creating and tailoring modules on the internet, working with a Dutch university. 
Duys is developing a similar algorithm-based e-learning platform that can be adapted by any medical student to his or her skills and knowledge levels. Weiss is no slouch in this department either; drawing on expertise and resources from the Division of Cardiology, she's collaborating with a senior registrar, Charl Viljoen, who wants to super-specialise in cardiology. With a small ZAR30 000 grant they're using in-house programming skills and a bank of cardiology electrocardiograms (ECGs) to create an on-line learning plat- form to plug a major learning gap - the interpretation of ECGs. 'We got complaints from people teaching sixth-years, saying that students don't retain their third-year ECG interpretation theory.' Online exercises now enable students from third to sixth year not only to interpret ECGs but to assess their own knowledge levels. She says that research studies both internationally and locally suggest that 'most doctors, unless they are cardiologists, suck at ECGs', and this bolstered her proposal and subsequent funding.
What is certain is that the impact of UCT's world-class Clinical Skills Centre will increasingly reverberate across the country and the continent as medical professionals emerge more proficient than ever before - with commensurate huge savings in lives and money.

\section{Chris Bateman}

chrisb@hmpg.co.za

S Afr Med J 2015;105(7):799-801

DOI:10.7196/SAMJnew.8758 